Check for updates

Cite this: RSC Adv., 2018, 8, 28836

\title{
Determination of solubility, stability and degradation kinetics of morin hydrate in physiological solutions $\dagger$
}

\author{
Ashok Kumar Jangid, ${ }^{a}$ Deep Pooja ${ }^{b}$ and Hitesh Kulhari (D) *a
}

\begin{abstract}
Natural drugs have emerged as potential alternatives to synthetic drugs to avoid their toxic effects. Morin hydrate $(\mathrm{MH})$ is a natural therapeutic agent, obtained from Maclura pomifera, Maclura tinctoria and Psidium guajava. Solubility and degradation kinetics of morin hydrate in different physiological media, namely, $0.1 \mathrm{~N} \mathrm{HCl}(\mathrm{pH}$ 1.2), sodium acetate buffer $(\mathrm{pH}$ 5.0), water $(\mathrm{pH}$ 7.0), phosphate buffer saline $(\mathrm{pH}$ 7.4) and tris base (pH 9.0), were investigated via classical spectroscopic methods. Stability studies of $\mathrm{MH}$ were performed to determine the effect of different $\mathrm{pH}$ media, temperature (room and freeze) and light on the degradation kinetics. Solubility and stability of $\mathrm{MH}$ varied significantly in different biological media and storage conditions. Solubility of $\mathrm{MH}$ was $\mathrm{pH}$-dependent and increased with the increase in $\mathrm{pH}$. Degradation kinetics and regression values $\left(r^{2}\right)$ values were calculated from the linear fitted models of zero, first and second order kinetics.
\end{abstract}

Received 15th May 2018

DOI: $10.1039 / c 8 r a 04139 c$

rsc.li/rsc-advances

\section{Introduction}

Toxicities of synthetic drugs have drawn attention towards alternative natural medicines. As per previous reports, only in the United States, about 100000 deaths occur each year due to the toxicities of synthetic drugs. ${ }^{1-3}$ Moreover, most of these deaths occur due to the toxicities of over-the-counter drugs, which are generally recognized as safe. ${ }^{4}$ Therefore, natural drugs have gained considerable attention due to their several advantages over synthetic drugs, including a broad range of therapeutic activity, fewer side effects, and structural complexity. A broad therapeutic index of such drugs helps to maintain the drug concentration within a therapeutic window, while structural complexity provides selective binding of drugs to their targets. ${ }^{5}$ More than a hundred clinical studies are ongoing for evaluation of the efficacies of natural drugs.

In general, natural drugs are obtained from their source in an extract form. Although extracts of natural plant sources are used routinely for therapeutic purposes in developing countries, quality control of such medicines is complicated and difficult. Therefore, an individual constituent or active ingredient, with well-defined structure and physicochemical properties, is preferred. Phytoconstituent is a major class of natural drugs and has been extensively studied for treating various

${ }^{a}$ School of Nano Sciences, Central University of Gujarat, Gandhinagar 382030, India. E-mail: hitesh.kulhar@cug.ac.in; Kulhari.h@gmail.com

${ }^{b}$ Pharmacology and Toxicology Division, CSIR-Indian Institute of Chemical Technology, Hyderabad-500007, India

$\dagger$ Electronic supplementary information (ESI) available. See DOI: 10.1039/c8ra04139c diseases, such as inflammation, hypocholesteraemia, diabetes, and cancer. Flavonoids are the major active ingredients in most of the phytoconstituents. Curcumin, rutin, quercetin, naringenin, and fisetin are the most explored bioflavonoids for their therapeutic applications. ${ }^{5-8}$

Morin hydrate (MH), a flavonoid, is obtained by hydroalcoholic extraction from Maclura pomifera, Maclura tinctoria and Psidium guajava. ${ }^{9} \mathrm{MH}$ has been reported to possess several pharmacological activities, such as anti-inflammatory, anticancer, antioxidant, antiarthritic, antifertility, antiplasmodic and antitumor. ${ }^{9-12}$ Haddad et al. extracted $\mathrm{MH}$ (purity $>90 \%$, HPLC) from psidium guajava leaves using hydroalcoholic solution $(70 \%) .^{13}$

Similar to other bioflavonoids, $\mathrm{MH}$ exhibits poor aqueous solubility $\left(28.7 \mu \mathrm{g} \mathrm{mL}^{-1}\right.$ in water), which leads to low oral bioavailability. ${ }^{14}$ Furthermore, $\mathrm{MH}$ is sensitive to the solvent used and $\mathrm{pH}^{15,16}$ Solubility and stability are two important physicochemical properties of a new drug candidate and affect its performance and formulation development process. Pharmacokinetic and pharmacodynamic performances of a formulation are dependent on the drug levels in blood plasma, tissues, and urine. After oral administration, the drug levels in plasma are dependent on absorption of the drug through gastrointestinal tract. Stomach and intestine are the major sites for absorption of a drug molecule. Therefore, it becomes critical to determine the solubility and stability of a drug at different $\mathrm{pH}$ conditions of GIT. Many studies have highlighted the therapeutic effects of $\mathrm{MH}$, but no systematic and adequate study on solubility and stability in different $\mathrm{pH}$ conditions in aqueous media is reported as yet. Only in a recent study, Yazdanshenas et al. (2017) determined the solubility of $\mathrm{MH}$ in various 
alcoholic solutions containing methanol, ethanol, propan-1-ol, propan-2-ol and butan-1-ol. ${ }^{17}$

In view of the above problems associated with $\mathrm{MH}$, we comparatively investigated the effect of $\mathrm{pH}$, storage temperature and light on the stability of MH. Solubility of MH was studied in different $\mathrm{pH}$ conditions and simulating the $\mathrm{pH}$ conditions of GIT and blood plasma. Another objective of the current study was to investigate the stability of $\mathrm{MH}$ in media at different $\mathrm{pH}$, which are routinely used during pharmaceutical formulation development.

\section{Experimental section}

\section{Chemicals and reagents}

$\mathrm{MH}$, trisma base and phosphate buffer saline (PBS) tablets were purchased from Sigma Aldrich (St. Louis, MO, USA). Hydrochloric acid, sodium acetate, and acetic acid were purchased from Rankem (Mumbai, India). High-performance liquid chromatography solvents, namely, acetonitrile and ortho-phosphoric acid were purchased from Merck Specialities Pvt. Ltd. (Mumbai, India).

\section{Analytical method}

MH was analyzed in different analytical solutions using a highperformance chromatography system (Waters, USA), equipped with a photodiode array detector and a C18 column (Water, 250 $\times 4.6 \mathrm{~mm}, 5 \mu \mathrm{m})$. Column temperature was maintained at $25 \pm$ $5{ }^{\circ} \mathrm{C}$. Mobile phase comprised acetonitrile (40\%) and water at $\mathrm{pH} 3.5$, adjusted with $0.1 \%$ ortho-phosphoric acid, $(60 \%)$ and was maintained at $1 \mathrm{~mL} \mathrm{~min}{ }^{-1}$ flow rate. Sample injection volume was $20 \mu \mathrm{L}$. The retention time of $\mathrm{MH}$ was $5.1 \mathrm{~min}$. Calibration graph was rectilinear in the concentration range of $0.1-5 \mu \mathrm{g} \mathrm{mL} \mathrm{m}^{-1}$, with a correlation coefficient of 0.999 .

\section{pH-dependent solubility of MH}

Solubility of MH was determined by the shake-flask method. Briefly, excess $\mathrm{MH}$ was added to amber coloured glass vials containing $10 \mathrm{~mL}$ of a series of aqueous solutions, namely, $0.1 \mathrm{~N}$ $\mathrm{HCl}$ (pH 1.2), sodium acetate buffer ( $\mathrm{pH}$ 5.0), double distilled water ( $\mathrm{pH} 7.0)$, phosphate buffer saline $(\mathrm{pH}$ 7.4) and tris base buffer ( $\mathrm{pH}$ 9.0). The samples were placed in an orbital shaker (to achieve uniform mixing) at $37^{\circ} \mathrm{C}$ (standard physiological temperature) for $12 \mathrm{~h}$. These samples were then filtered through $0.22 \mu \mathrm{m}$ membrane filters and analyzed for MH content by highperformance liquid chromatography. The samples were also scanned by UV-Visible spectrophotometer to check the integrity and shift in the peak at different $\mathrm{pH}$.

\section{Effect of light and temperature on stability}

Stability studies were performed in $0.1 \mathrm{~N} \mathrm{HCl}$, sodium acetate buffer ( $\mathrm{pH}$ 5.0), double distilled water ( $\mathrm{pH}$ 7.0), phosphate buffer saline (pH 7.4) and tris base buffer (pH 9.0) containing MH with concentration of $25 \mu \mathrm{g} \mathrm{mL}{ }^{-1}$. For this experiment, a stock solution of $\mathrm{MH}\left(1 \mathrm{mg} \mathrm{mL}^{-1}\right)$ was prepared in ethanol and diluted with different $\mathrm{pH}$ solutions to achieve the final $\mathrm{MH}$ concentration of $25 \mu \mathrm{g} \mathrm{mL}{ }^{-1}$. The solutions were kept in different conditions, i.e., at room temperature $\left(25{ }^{\circ} \mathrm{C}\right)$ (light or dark) and at refrigeration temperature $\left(4^{\circ} \mathrm{C}\right)$ (light or dark). A simple visible light lamp was used as the light source. For dark conditions, the vials were covered by an aluminium foil to protect them from light. At predetermined time intervals, aliquots were withdrawn, kept at RT for 5 min and measured by HPLC. Drug degradation rates were determined for zero order (\% drug degradation $v s$. time), first order (log\% drug degradation $v s$. time) and second order (1/ (\% drug degradation) vs. time).

\section{Statistical analysis}

All experiments were performed in triplicate and results are reported as a mean \pm standard deviation. The $p$-values less than 0.05 were considered as statistically significant.

\section{Results and discussion}

\section{Solubility study of MH}

Solubility of a drug molecule is an important physicochemical property, which directly affects the drug discovery and development process. Solubility of $\mathrm{MH}$ was determined by the shakeflask method and Table 1 summarizes the solubility of $\mathrm{MH}$ in different solvents at room temperature. $\mathrm{MH}$ solubility was found to be $32.69 \pm 1.63,14.88 \pm 2.43,28.72 \pm 0.97,54.86 \pm 2.05,505.9$ $\pm 14.61 \mu \mathrm{g} \mathrm{mL}{ }^{-1}$ in $0.1 \mathrm{~N} \mathrm{HCl}(\mathrm{pH} 1.2)$, sodium acetate buffer ( $\mathrm{pH}$ 5.0), double distilled water ( $\mathrm{pH} 7.0)$, phosphate buffer saline $(\mathrm{pH}$ 7.4) and tris base buffer (pH 9.0), respectively.

The results clearly indicate the $\mathrm{pH}$-dependent solubility of $\mathrm{MH}$. Lowest solubility of $\mathrm{MH}$ was observed at $\mathrm{pH} 5.0$ due to the formation of an individual acetate ion sphere and many hydration spheres in bulk of the system where ion-dipole interactions are more dominant compared to the hydrophobic layer formed by acetate ions (Fig. 1a). This may be also due to the presence of $\mathrm{Na}^{+}$ions, which may restrict the interaction between free acetate ions and MH. Similarly, at pH 1.2, the presence of excess $\mathrm{Cl}^{-}$ions rapidly leads to the formation of individual hydration spheres (Fig. 1b) with a partial negative charge. These $\mathrm{Cl}^{-}$hydration spheres generate ion-hydrophobic interactions between hydration ions and $\mathrm{MH}$ molecules, which increase the solubility as compared to that in $\mathrm{pH} 5.0$ system. However, a slight change in $\mathrm{pH}$ from neutral to basic value ( $\mathrm{pH} 7$ to 7.4 ) led to a significant $(p$ $<0.05$ ) increase in the solubility of MH. Owing to this, the larger sized $\mathrm{PO}^{3-}$ ions form larger aqueous aggregates in bulk as compared to those in $\mathrm{HCl}$ and $\mathrm{SAB}$. Moreover, $\mathrm{pH}$ of the system is controlled by $\mathrm{Cl}^{-}, \mathrm{Na}^{+}$and $\mathrm{K}^{+}$ions via formation of the individual hydration spheres (Fig. 1c). ${ }^{18} \mathrm{MH}$ has significantly higher

Table 1 Solubility of morin hydrate in different solvents

\begin{tabular}{lcc}
\hline Solvent & Solvent $\mathrm{p} K_{\mathrm{a}}$ & Solubility $\left(\mu \mathrm{g} \mathrm{mL}{ }^{-1}\right)$ \\
\hline 0.1 N hydrochloric acid & -7.0 & $32.69 \pm 1.63$ \\
Sodium acetate buffer, pH 5.0 & 4.75 & $14.88 \pm 2.43$ \\
Distilled water, pH 7.0 & 14 & $28.72 \pm 0.97$ \\
Phosphate buffer saline, pH 7.4 & 12.35 & $54.86 \pm 2.05$ \\
Tris base buffer, pH 9.0 & 8.07 & $505.09 \pm 14.61$
\end{tabular}




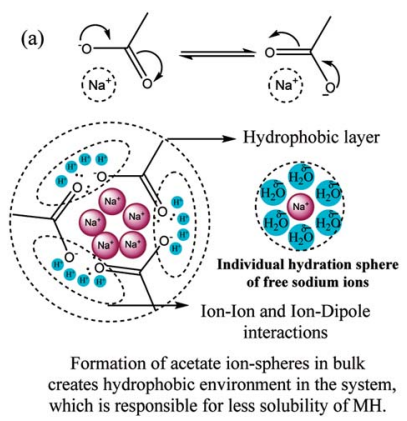

(b)

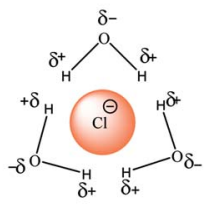

Excess small-sized $\mathrm{Cl}^{-}$ions rapidly engage with the hydration sphere to form clusters in the medium, resulting in the blue-shift.

$\underset{\mathrm{pH}}{\text { (c) } 1 \mathrm{X} \text { Phosphate buffer saline } \longrightarrow} \longrightarrow 10 \mathrm{mM} \mathrm{PO}_{4}{ }^{3-}+137 \mathrm{mM} \mathrm{NaCl}+2.7 \mathrm{mM} \mathrm{KCl}$

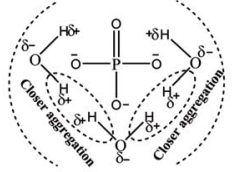

Formation of larger aqueous aggregates, as compared to those in $\mathrm{HCl}$ and $\mathrm{SAB}$, easily engage with $\mathrm{MH} ; \mathrm{pH}$ of the system is controlled by the presence of $\mathrm{Cl}^{-}, \mathrm{Na}^{+}$ and $\mathrm{K}^{+}$ions via formation of individual hydration spheres. (d)

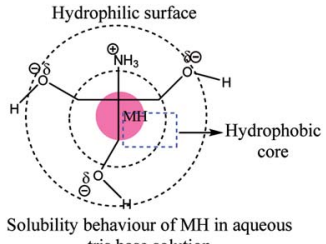

tris base solution
Fig. $1 \mathrm{pH}$-dependant comparative aqueous interactions of (a) $\mathrm{Cl}^{-}$, (b) acetate ions, (c) phosphate ions and (d) tris base with individual hydration sphere formation.

solubility in basic medium than in neutral and acidic media (Table 1). The enhanced solubility at higher $\mathrm{pH}$ can be explained by the ionization (deprotonation) of $\mathrm{MH}$ at higher $\mathrm{pH}$. The enhanced solubility may also be observed due to amphiphilic behaviour of tris base in water (Fig. 1d), which led to generation of more binding sites for $\mathrm{MH}$. There was an insignificant $(p>$ 0.05 ) difference in the solubility of $\mathrm{MH}$ at acidic and neutral $\mathrm{pH}$. However, a small change in $\mathrm{pH}$ towards basic $\mathrm{pH}$ (from 7 to 7.4) led to more than 3-fold increase in the solubility of $\mathrm{MH} . \mathrm{p} K_{\mathrm{a} 1}$ and $\mathrm{p} K_{\mathrm{a} 2}$ of $\mathrm{MH}$ are 3.46 and 8.1, respectively, suggesting that the deprotonation of $\mathrm{C} 7-\mathrm{OH}$ of benzoyl ring (Fig. 2) occurs in basic medium. This deprotonation facilitated resonance with the $\mathrm{C} 4$ $(>\mathrm{C}=\mathrm{O})$ moiety, resulting in tautomerization $(>\mathrm{C}=\mathrm{O} \leftrightarrow \mathrm{C}-\mathrm{OH})$, which was observed at $400 \mathrm{~nm}$. This suggested that the carbonyl group at $\mathrm{C} 4$ could undergo nucleophilic substitution, catalyzed by $\mathrm{H}_{3} \mathrm{O}^{+}$ions, to show keto-enol tautomerization at $\mathrm{pH} 9.0\left(\mathrm{p} K_{\mathrm{a}}=\right.$ 8.07). Hence, the electron rich sites generated in MH molecules could also be responsible for higher solubility of $\mathrm{MH}$ in basic medium. $^{19}$

\section{Qualitative and solvent effect analysis via UV-Visible spectrophotometer}

UV-Vis spectrum of $\mathrm{MH}$ at a concentration of $10 \mu \mathrm{g} \mathrm{mL} \mathrm{L}^{-1}$ was recorded in the wavelength range from 200 to $500 \mathrm{~nm}$ (Fig. 3).

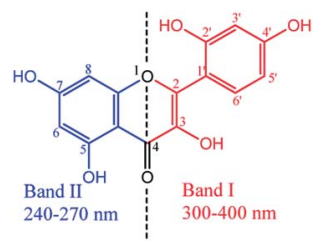

Fig. 2 Molecular structure of morin hydrate.

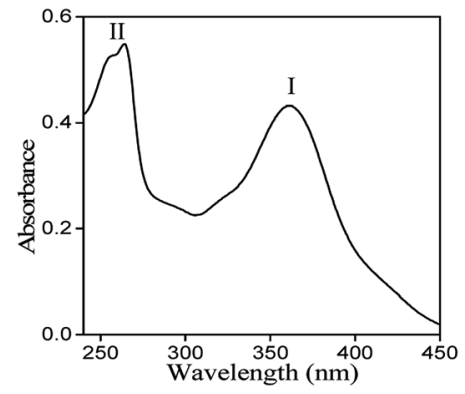

Fig. 3 UV-Visible spectrum of morin hydrate $\left(10 \mu \mathrm{g} \mathrm{mL}^{-1}\right)$ in ethanol.

Two absorption bands were observed at $363 \mathrm{~nm}$ (Band I) and at $263 \mathrm{~nm}$ (Band II).

The observed band-I is attributed to the presence of cinnamoyl system (B-C ring), while band II corresponds to the benzoyl moiety (A-C ring). These peaks arise due to $\pi \rightarrow \pi^{*}$ transitions and conjugated system of rings $\mathrm{A}$ and $\mathrm{B}$ attached to the middle ring (C) in the $\mathrm{MH}$ molecule. Generally, deprotonation of $-\mathrm{OH}$ groups in polyphenolic compounds forms a negative oxygen ion $\left(-\mathrm{O}^{-}\right)$, which delocalizes $\pi$-electrons in the molecule and leads to a bathochromic or red shift in the UV spectrum. ${ }^{20}$ In the current study, maximum absorbance wavelength $\left(\lambda_{\max }\right)$ of $\mathrm{MH}$ in ethanol was observed at $363 \mathrm{~nm}$ and was shifted to $350,367,389,390$ and $400 \mathrm{~nm}$ at $\mathrm{pH} 1.2,5.0,7.0,7.4$ and 9.0, respectively (Fig. 4). These shifts in the $\lambda_{\max }$ of band I at different $\mathrm{pH}$ can be explained on the basis of $\mathrm{p} K_{\mathrm{a}}$ value of $\mathrm{MH}$ and the effect of $\mathrm{pH}$ on its ionization. $\mathrm{p} K_{\mathrm{a} 1}$ (3.46) of $\mathrm{MH}$ is lower than $\mathrm{p} K_{\mathrm{a}}$ of other bioflavonoids, such as kaempferol (8.2), rutin (6.74) and quercetin (6.74). ${ }^{17}$ This lower $\mathrm{p} K_{\mathrm{a} 1}$ value of $\mathrm{MH}$ is due to the presence of three $-\mathrm{OH}$ groups on the cinnamoyl system (B-C ring). In this system, the para positioned -OH group shows large conjugation with $\mathrm{B}$ and $\mathrm{C}$ rings of $\mathrm{MH}$. Therefore, it is easily dissociated in basic medium as compared to the $-\mathrm{OH}$ group present in ring A. In other bioflavonoids, such as quercetin, intramolecular hydrogen bonding between the $m$ - and $p$ -

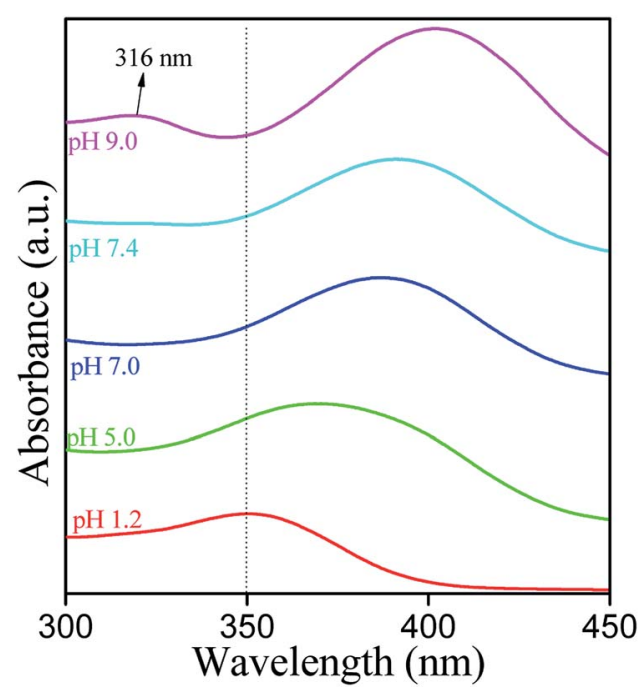

Fig. 4 UV absorption spectra of morin hydrate $\left(25 \mu \mathrm{g} \mathrm{mL} L^{-1}\right)$ in different biological $\mathrm{pH}$ media. 
positioned - $\mathrm{OH}$ groups of cinnamoyl system prevents the dissociation of $\mathrm{H}^{+}$from -OH groups, resulting in higher $\mathrm{p} K_{\mathrm{a}}$ values. ${ }^{21}$ However, in $\mathrm{MH}, p$-positioned -OH group could not participate in intramolecular hydrogen bonding, exhibiting lower $\mathrm{p} K_{\mathrm{a}}$ value.

In basic medium, the $\lambda_{\max }$ was shifted to $400 \mathrm{~nm}$ as compared to that in pure ethanol, and a new band in the range of 310 to $350 \mathrm{~nm}$ was also observed, which corresponds to two isosbestic points at 263 and $363 \mathrm{~nm}$. It has been reported that the solubility, stability, and reactivity of bioflavonoids increases with an increase in $\mathrm{pH}$ of the solution due to higher deprotonation of hydroxyl groups in the B ring. ${ }^{22,23}$ Since the $-\mathrm{OH}$ groups of $\mathrm{MH}$ are all deprotonated at $\mathrm{pH}$ 9.0, a lone pair of electrons on the $\mathrm{C} 3$ oxygen of $\mathrm{MH}$ may delocalize to the ring $\mathrm{B}$ through resonance. Consequently, the electron density of ring $\mathrm{B}$ increases, which allows it to be easily oxidized. In addition, stabilization of the by-product, as a result of tautomerization in the cinnamoyl system (ring B and C), further facilitated the reaction to proceed with degradation of $\mathrm{MH}$ (Fig. 5).

Generally, in acidic medium, $\mathrm{MH}$ chelates with metal ions at the $2^{\prime}-\mathrm{OH}$ and $4^{\prime}-\mathrm{OH}$ groups of ring $\mathrm{B}$ and the $3-\mathrm{OH}$ group of ring $\mathrm{C}$. This may be due to the ionization of $4^{\prime}-\mathrm{OH} .{ }^{15}$ However, in the current study, the chelation sites seem to be weaker compared to the $3-\mathrm{OH}$ group and $>\mathrm{C}=\mathrm{O}$ group of ring $\mathrm{C}$ (Fig. 6). Hence, the absorption peak shifted to $350 \mathrm{~nm}$ from $363 \mathrm{~nm}$. Thus, the shift in the absorption band depicts the different structural behaviour of $\mathrm{MH}$ molecule in different biological media.

\section{Degradation kinetics of MH}

Chemical stability of bioflavonoid molecules at variable temperatures and solvent systems is of utmost importance for pharmaceutical applications. ${ }^{21-23}$ Storage and working stability studies of drug molecules can help understand the quality of drugs in different biological media, the required storage conditions, and also aid the design of formulations for therapeutic applications. In this study, the degradation kinetics of hydrophobic $\mathrm{MH}$ was investigated in $\mathrm{pH}$ 1.2, $\mathrm{pH}$ 5.0, $\mathrm{pH}$ 7.0, $\mathrm{pH}$ 7.4 and $\mathrm{pH} 9.0$ solvent, after storing at freezing and room temperatures under light and dark conditions.

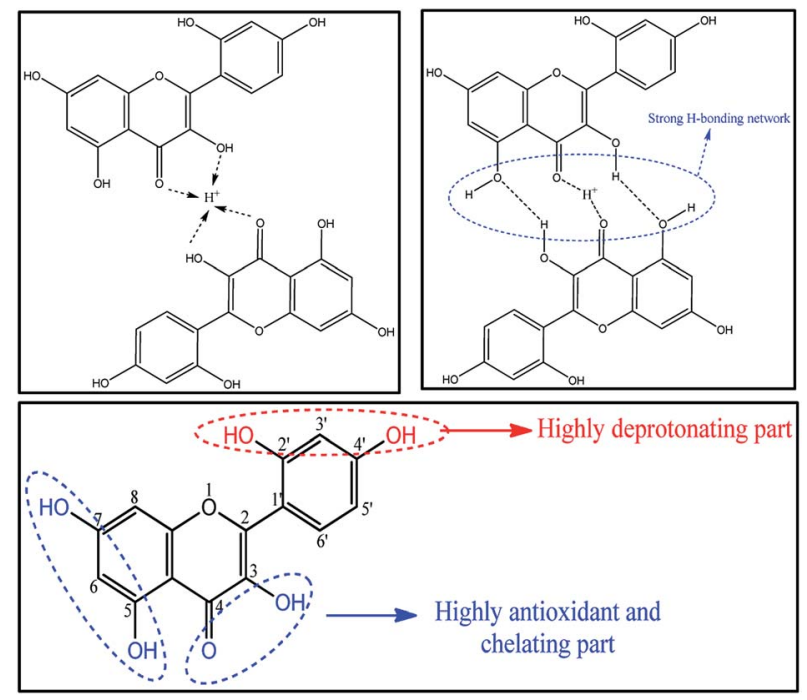

Fig. 6 Possible mechanism for bathochromic shift of $\lambda_{\max }$ of morin hydrate in $0.1 \mathrm{~N} \mathrm{HCl}$ and possible active sites in morin hydrate.

Fig. 7-9 show the degradation kinetics of MH under light or dark conditions. Rapid degradation of $\mathrm{MH}$ was observed in $\mathrm{pH}$ 9.0 buffer along with a change in colour. After $96 \mathrm{~h}$, about 94 , 93.2, 93.4 and $33.4 \%$ of MH was degraded in RT light, RT dark, freeze light and freeze dark conditions, respectively. This can also be evidenced from the effect of solvent, as shown in Fig. 4 and S1-S5 of ESI, $\dagger$ where a new absorbance band was observed between 310 to $350 \mathrm{~nm}$ in the UV spectrum, indicating the oxidation of $\mathrm{MH}$ in basic medium (Fig. 5).

In contrast, in acidic or nearly neutral conditions, degradation of MH was slower compared to that in basic medium. In the acidic or near to neutral $\mathrm{pH}$ conditions the degradation was found to be minimum (Fig. S1 and S2 $\dagger$ ). For instance, the following degradation values were observed after $96 \mathrm{~h}$ storage under RT light, RT dark, freeze light and freeze dark conditions: $\mathrm{pH}$ 1.2: $30.41 \%, 10.73 \%, 46.02 \%$ and $69.46 \%$; pH 5.0: $42.75 \%, 12.12 \%, 82.91 \%$ and $10.46 \%$; pH $7.0: 26.74 \%, 10.36 \%$, $80.48 \%$ and $15.28 \%$; and $\mathrm{pH} 7.4: 48.26 \%, 13.18 \%, 77.68 \%$ and $9.22 \%$. Slow degradation in acidic medium may be due to the reduction of $>\mathrm{C}=\mathrm{O}$ bond of $\mathrm{MH}$. The presence of free $-\mathrm{OH}$

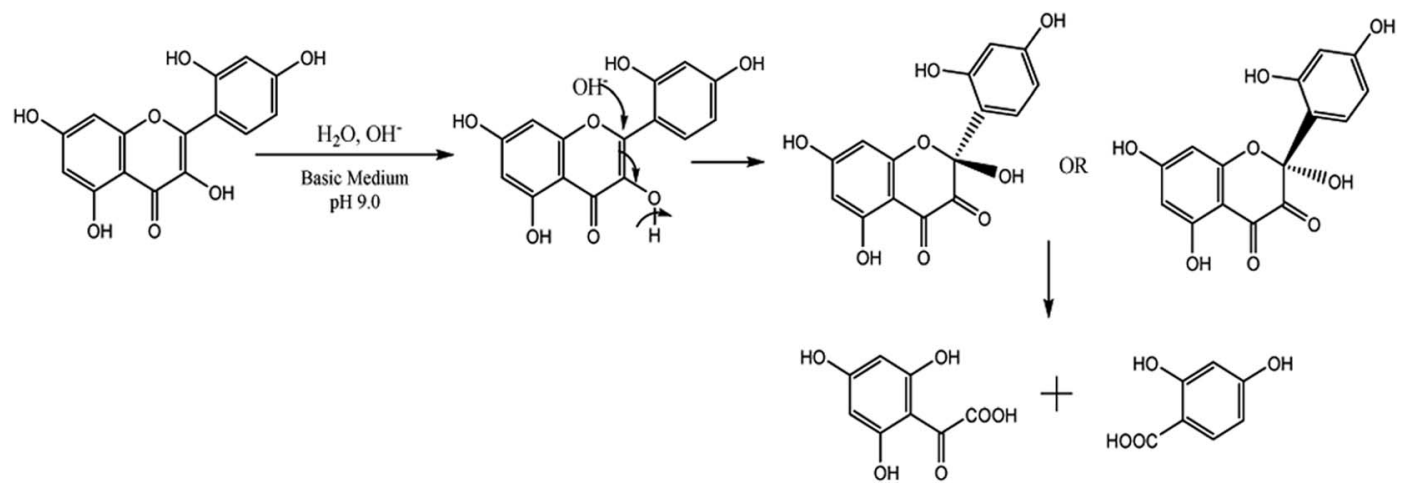

Fig. 5 Possible degradation pathway of morin hydrate in alkaline medium. 

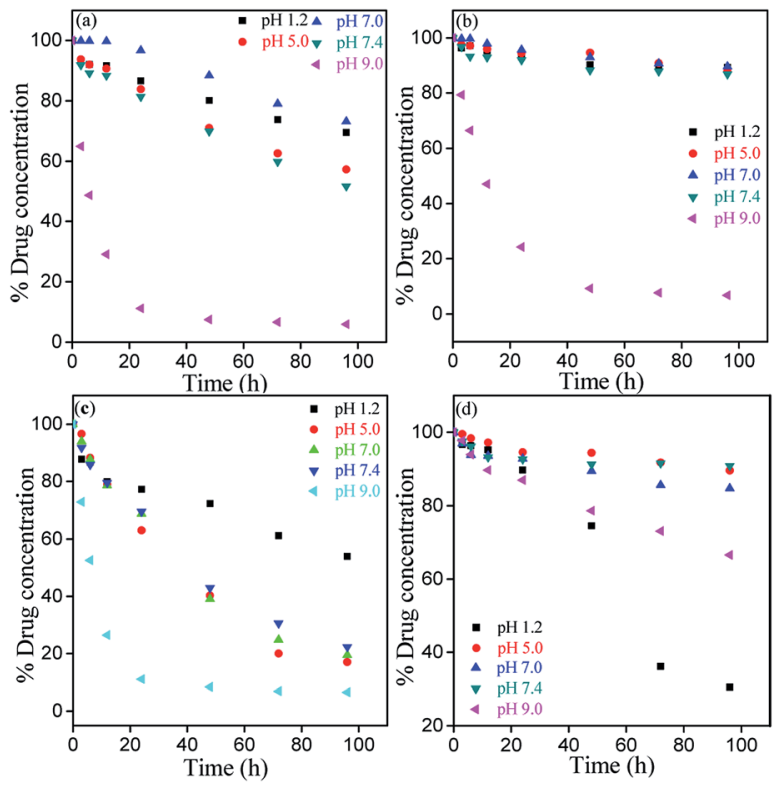

Fig. 7 Zero order kinetics for degradation of $\mathrm{MH}$ at different storage conditions: (a) room temperature light, (b) room temperature dark, (c) freeze temperature light, and (d) freeze temperature dark.

groups causes clustering, followed by strong intermolecular hydrogen bonding (Fig. 10).

However, maximum degradation of $\mathrm{MH}$ in context of storage conditions was found in the freeze temperature light condition, where MH degraded by $46.07 \%, 82.91 \%, 80.48 \%, 77.68 \%$ and 93.44\% in pH 1.2, pH 5.0, pH 7.0, pH 7.4 and pH 9.0 media, respectively (Fig. S1-S5†). These results clearly indicated that the stability of $\mathrm{MH}$ was more affected by light than temperature, and MH degraded faster in freeze-light condition. This may be
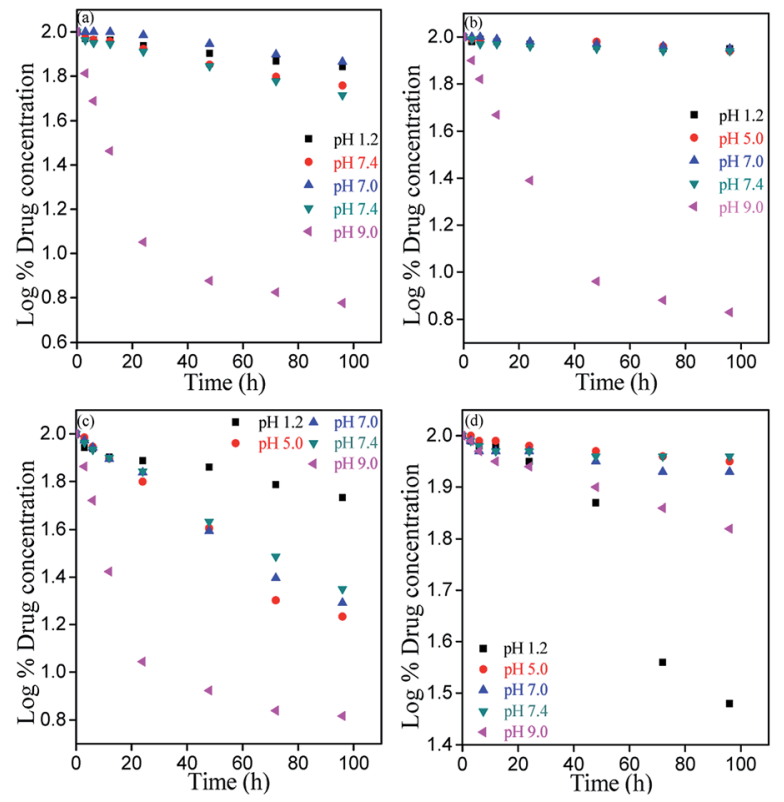

Fig. 8 First-order kinetics for degradation of $\mathrm{MH}$ at different storage conditions: (a) room temperature light, (b) room temperature dark, (c) freeze temperature light, and (d) freeze temperature dark.
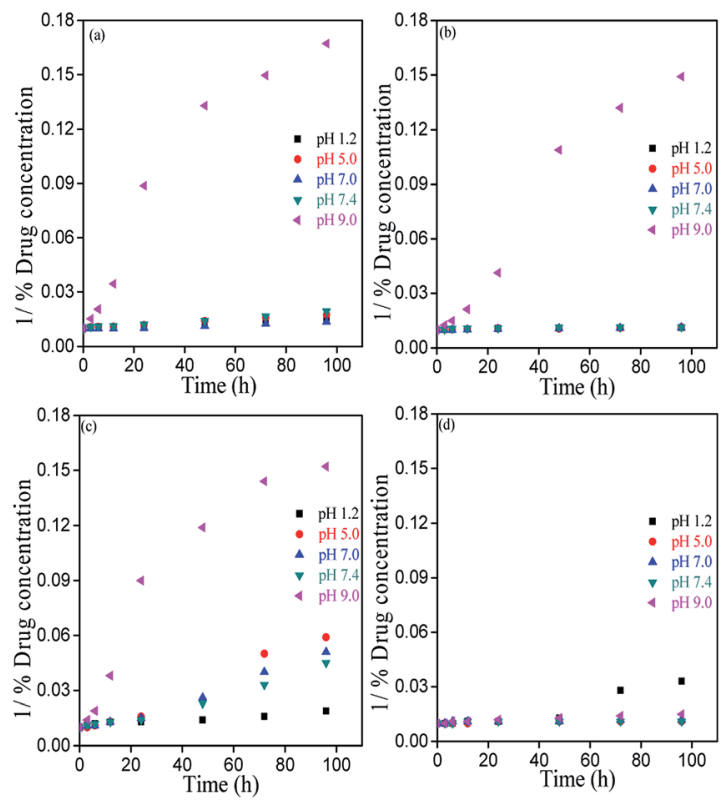

Fig. 9 Second order kinetics for degradation of $\mathrm{MH}$ at different storage conditions: (a) room temperature light, (b) room temperature dark, (c) freeze temperature light, and (d) freeze temperature dark.

due to the clustering nature of $\mathrm{MH}$ molecules at lower temperature.

The stability of $\mathrm{MH}$ was further influenced by the $-\mathrm{OH}$ group at $\mathrm{C}-3$ position. This can be explained by the $-\mathrm{OH}$ group present in 3 position of ring $\mathrm{C}$, which first activates the $\mathrm{C} 2-\mathrm{C} 3$ bonds $^{24,25}$ and then activates the $\mathrm{C} 2-\mathrm{O} 1$ in presence of light, which leads to the opening of ring $\mathrm{C}$ of $\mathrm{MH}$.

In order to evaluate the working and storage stability of $\mathrm{MH}$ solution, aqueous solutions at different $\mathrm{pH}$ were studied. The results illustrated in Fig. 11 show the effect of different $\mathrm{pH}$ solvents on the storage stability of $\mathrm{MH}$ at freeze and room<smiles>CC(C)C(C)C</smiles>

Reduction of $>\mathrm{C}=\mathrm{O}$ in acidic medium

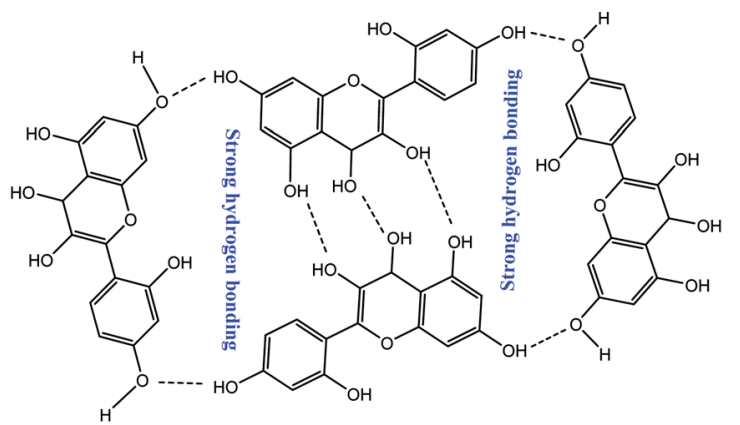

Clustering of the $\mathrm{MH}$ molecules followed by the strong hydrogen bonding is responsible for loss of conjugation under freeze-dark conditions

Fig. 10 Possible time-dependent reduction mechanism of $\mathrm{MH}$ in acidic medium with aggregation behaviour of the reduced $\mathrm{MH}$ molecules. 


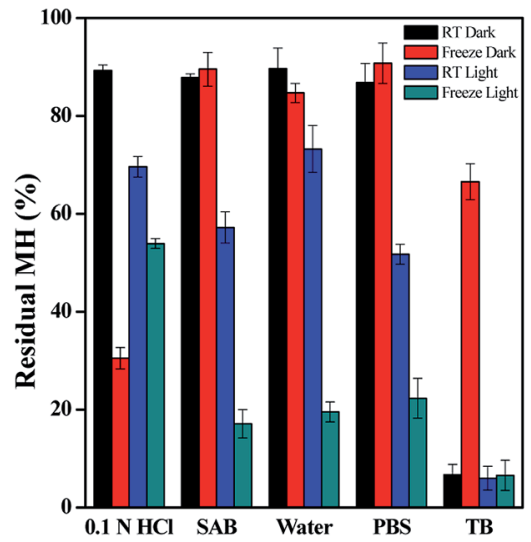

Fig. 11 Effect of different storage condition on the stability of $\mathrm{MH}$ in various media.

temperature. $\mathrm{MH}$ shows maximum stability at RT in dark condition at $\mathrm{pH}$ from 1.2 to 7.4. The minimum stability was found at $\mathrm{pH} 9.0$ in all storage conditions. ${ }^{26}$ In RT light condition, slightly similar stability was observed for $\mathrm{pH} 1.2, \mathrm{pH} 5.0$, pH 7.0 and $\mathrm{pH} 7.4$ solvents.

In addition, regression coefficient $\left(r^{2}\right)$ values and degradation rates of $\mathrm{MH}$ were calculated from the slope of the best-fitted kinetic models. These calculations were performed for data upto $24 \mathrm{~h}$, where the changes in concentrations were linear. (Table S1 and S2, ESI $\dagger$ ). Degradation rates increased from acidic to basic pH. Hence, all these results indicated the specific acid and base catalysed effect on MH stability. ${ }^{26}$ From the $r^{2}$ values, we can also generalize trends in the drugs degradation rate and stability. The results indicated that the degradation rate was lower in acidic and neutral conditions than in basic medium. In basic medium, higher degradation rates were observed at all storage conditions. Overall, $\mathrm{MH}$ solutions stored in dark were stable at both RT and freeze temperature conditions, except for samples of $\mathrm{pH} 9.0$.

\section{Gibbs free energy $(\Delta G)$ for comparative degradations}

$\Delta G$ is determined for studying degradation spontaneity of $\mathrm{MH}$ in different $\mathrm{pH}$ solutions. $\Delta G$ was calculated using the following equation:

$$
\Delta G=-2.303 R T \log \left(A / A_{0}\right)
$$

where $A$ and $A_{0}$ are the absorbance values of sample at $0 \mathrm{~h}$ and after $96 \mathrm{~h}$, respectively.

Fig. 12 shows the $\Delta G$ values for the $\mathrm{pH}$-dependent $\mathrm{MH}$ solutions in different storage conditions to infer the spontaneous degradation of $\mathrm{MH} . \Delta G<0$ supports the spontaneous degradation of $\mathrm{MH}$ in different conditions. Furthermore, $\mathrm{pH}$ as well as the stability of $\mathrm{MH}$ attained from the kinetic equilibrium contributes to $\Delta G$. Hence, $\Delta G<0$ could be obtained due to induced molecular oscillations by the changing $\mathrm{pH}$ of $\mathrm{MH}$ system that may be responsible for the degradations.

However, the free energy trends for different conditions and $\mathrm{pH}$ are $9.0>7.4>5.0>7.0>1.2,9.0>7.4>5.0>1.2>7.0,9.0>$ $5.0>7.0>7.4>1.2$ and $1.2>9.0>7.0>5.0>7.4$ at RT light, RT
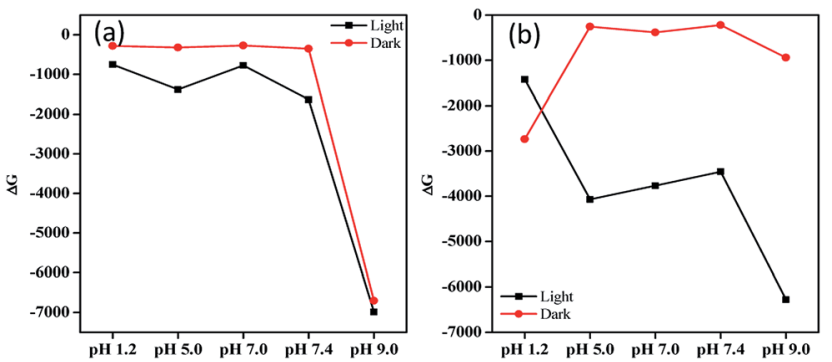

Fig. 12 Free energy of different $\mathrm{pH}$ systems (a) at room temperature and (b) at freeze temperature.

dark, freeze light and freeze dark conditions, respectively. Temperature, $\mathrm{pH}$, and light all affect the relative stability of $\mathrm{MH}$. At both RT dark and light conditions, $\Delta G$ decreased sharply for pH 9.0 compared to acidic and neutral conditions (Fig. 12a). However, in freeze conditions, $\Delta G$ shows random trends of instability for the systems.

\section{Conclusions}

Aqueous solubility is the first and most important parameter for designing a drug delivery system for a new therapeutic entity. In this study, solubility, stability, degradation rates and $\Delta G$ of $\mathrm{MH}$ in different aqueous solutions of different $\mathrm{pH}$ were evaluated. Solubility and stability of $\mathrm{MH}$ in different solutions have significantly varied trends with solution compositions. In summary, at room temperature and dark conditions, $\Delta G$ is relatively high. Hence, under this condition, the solutions and formulations of $\mathrm{MH}$ could be highly stable. Therefore, results from this study will be useful for pharmaceutical scientists in the handling of working solutions of $\mathrm{MH}$ and in designing suitable formulations for delivery of $\mathrm{MH}$. A clear $\mathrm{pH}$-dependent solubilisation of $\mathrm{MH}$ was observed. $\mathrm{MH}$ was found to be highly unstable at pH 9.0; however, it was metastable in acidic and neutral media. Comparatively, $\mathrm{pH}$ and light are the major factors affecting stability of $\mathrm{MH}$ rather than temperature.

\section{Conflicts of interest}

The authors declare that they have no conflict of interest.

\section{Acknowledgements}

The authors would like to thank Central University of Gujarat, Gandhinagar for providing necessary facilities and support. $\mathrm{H}$. K. acknowledges Department of Science and Technology, New Delhi for an INSPIRE Faculty Award. A. K. J. acknowledges University Grant Commission for a PhD fellowship.

\section{References}

1 D. Pooja, H. Kulhari, M. K. Singh, S. Mukherjee, S. S. Rachamalla and R. Sistla, Colloids Surf., B, 2014, 121, 461-468.

2 H. Kulhari, D. P. Kulhari, M. K. Singh and R. Sistla, Colloids Surf., A, 2014, 443, 459-466. 
3 T. S. Reddy, V. G. Reddy, H. Kulhari, R. Shukla, A. Kamal and V. Bansal, Eur. J. Med. Chem., 2016, 117, 157-166.

4 A. Karimi, M. Majlesi and M. Rafieian-Kopaei, J. Nephropharmacol., 2015, 4, 27-30.

5 R. Hanif, L. Qiao, S. J. Shiff and B. Rigas, J. Lab. Clin. Med., 1997, 130, 576-584.

6 M. Kharat, Z. Du, G. Zhang and D. J. McClements, J. Agric. Food Chem., 2017, 65, 1525-1532.

7 A. Bakowska, A. Z. Kucharska and J. Oszmianski, Food Chem., 2003, 81, 349-355.

8 H. Chaaban, I. Ioannou, C. Paris, C. Charbonnel and M. Ghoul, J. Photochem. Photobiol., A, 2017, 336, 131-139.

9 P. K. Shetty, V. Venuvanka, H. V. Jagani, G. Honnappa Chethan, V. S. Ligade, P. B. Musmade, U. Y. Nayak, M. S. Reddy, G. Kalthur, N. Udupa, C. Mallikarjuna Rao and S. Mutalik, Int. J. Nanomed., 2015, 10, 6477-6491.

10 Q. F. Zhang, Y. J. Fu, Z. W. Huang, X. C. Shangguang and Y. X. Guo, J. Agric. Food Chem., 2013, 61, 12085-12091.

11 H. M. Abuohashish, S. S. Al-Rejaie, K. A. Al-Hosaini, M. Y. Parmar and M. M. Ahmed, Diabetol. Metab. Syndr., 2013, 5, 5.

12 P. Ghosh, S. Bag, S. Roy and E. Subramani, RSC Adv., 2016, 6, 101415-101429.

13 A. E. El-Haddad, N. M. Sheta and S. A. Boshra, AAPS PharmSciTech, 2018, 19, 2346-2357.

14 A. Y. Waddad, S. Abbad, F. Yu, W. L. L. Munyendo, J. Wang, H. Lv and J. Zhou, Int. J. Pharm., 2013, 456, 446-458.
15 Q. K. Panhwar, S. Memon and M. I. Bhanger, J. Mol. Struct., 2010, 967, 47-53.

16 H. R. Park, S.-E. Im, J.-J. Seo, B.-G. Kim, J. A. Yoon and K.-M. Bark, Photochem. Photobiol., 2015, 91, 280-290.

17 R. Yazdanshenas and F. Gharib, J. Mol. Liq., 2017, 233, 9-14. 18 A. K. Jangid, P. Malik and M. Singh, J. Mol. Liq., 2018, 259, 439-452.

19 M. Tungjai, W. Poompimon, C. Loetchutinat, S. Kothan, N. Dechsupa and S. Mankhetkorn, Open Drug Delivery J., 2008, 2, 10-19.

20 A. Y. Waddad, S. Abbad, F. Yu, W. L. L. Munyendo, J. Wang, H. Lv and J. Zhou, Int. J. Pharm., 2013, 456, 446-458.

21 S. Tommasini, D. Raneri, R. Ficarra, M. L. Calabrò, R. Stancanelli and P. Ficarra, J. Pharm. Biomed. Anal., 2004, 35, 379-387.

22 D. H. Jornada, G. F. Dos Santos Fernandes, D. E. Chiba, T. R. F. De Melo, J. L. Dos Santos and M. C. Chung, Molecules, 2016, 21, 42.

23 A. J. Smith, P. Kavuru, L. Wojtas, M. J. Zaworotko and R. D. Shytle, Mol. Pharm., 2011, 8, 1867-1876.

24 G. J. Smith, S. J. Thomsen, K. R. Markham, C. Andary and D. Cardon, J. Photochem. Photobiol., A, 2000, 136, 87-91.

25 S. Ramešová, R. Sokolová, I. Degano, J. Bulíčková, J. Žabka and M. Gál, Anal. Bioanal. Chem., 2012, 402, 975-982.

26 X. Liang, Z. Liu, H. Shi, Y. Zhang, S. Wang, K. Bi and X. Chen, J. Pharm. Anal., 2017, 7, 118-122. 